\title{
Factors Governing Glucose Induced Elevation of Cyclic 3'5' AMP Levels in Pancreatic Islets
}

\author{
W. S. Zawalich, R. C. Karl, J. A. Ferrendelli and F. M. Matschinsky \\ Dept. of Pharmacology, Washington University Medical School, St. Louis, Missouri, USA
}

Received: November 19, 1974, and in revised form: April 1, 1975

\begin{abstract}
Summary. Adenosine 3',5'-cyclic monophosphate (cAMP) levels of isolated perifused pancreatic islets were elevated by high levels of glucose concomitantly with initiation of enhanced insulin secretion. The rise of cAMP was biphasic and seemed to be related to the temporal biphasic kinetics of insulin release. However, the temporal profiles of cAMP level changes and of insulin release differed; the major rise of the cAMP levels was seen during the initial phase, whereas insulin secretion was more pronounced during the second phase of release. Glucose-induced cAMP elevation required the presence of extracellular $\mathrm{Ca}^{++}$. Mannoheptulose com-
\end{abstract}

pletely blocked cAMP elevation due to high glucose. Exogenous insulin which has been shown by others to inhibit insulin secretion in vitro, blunted the glucose-induced cAMP rise. These observations and data in the literature are compatible with the concept that under physiological conditions glucose governs the intracellular cAMP levels in a $\mathrm{Ca}^{++}$ dependent manner - either directly or indirectly through metabolic effects.

Key words: Glucose, cyclic AMP, calcium, insulin, insulin secretion, receptor mechanism, second messenger.
The precise role of $3^{\prime}, 5^{\prime}$-cyclic adenosine monophosphate (cAMP) in the complex process of insulin release from pancreatic islets is poorly defined. There is no question that cAMP can influence profoundly B-cell function, as demonstrated by the fact that methylxanthines [1], cAMP [2] and dibutyrylcAMP [1] all greatly potentiate glucose provoked insulin release (although they are very inefficient in causing hormone release in the absence of glucose). Furthermore, enteric peptide hormones [4] glucagon $[2,5]$, and the $\beta$-adrenergic agonist isoproterenol [3], substances which activate islet adenylate cyclase, also potentiate glucose-provoked insulin release, whereas the $\alpha$-adrenergic agonist, epinephrine, which lowers cAMP in isolated pancreatic islets [7] blocks glucosestimulated insulin release [6]. It remains an open question whether insulin release resulting from glucose, the major physiological B-cell stimulus, involves elevation of cAMP levels as an obligatory step. In several studies it was found that cAMP was elevated in isolated pancreatic islets exposed to high glucose [8-14]; however in an equally large number of papers it was reported that glucose alone did not alter the cAMP levels of islet tissue $[15,16]$ or had only a small transient effect [17]. Some have found that high glucose elevated cAMP when a phosphodiesterase inhibitor was present $[8,9,17]$ others, however, did not confirm this phenomenon $[15,16]$.

This is a report of some of the results we have obtained in an effort to help clarify the issue.

The time courses of glucose-induced insulin release and possible related fluctuations in cAMP concentrations in islet tissue were investigated. Since glu- cose-induced insulin release requires extracellular $\mathrm{Ca}^{++}[18]$ and since this cation modifies adenylate cyclase activity in intact cells and in cell-free systems from many tissues [19], experiments were designed to delineate any role $\mathrm{Ca}^{++}$might have in regulating cAMP levels in islets. In addition, since mannoheptulose and insulin have been used to modulate the endocrine response of the B-cells $[6,20]$, the possible influence of these agents on the cAMP system was investigated.

\section{Materials and Methods}

Islets from fed male Sprague-Dawley rats (Holtzman, Madison, Wisconsin) were isolated according to the method of Lacy and Kostianovsky [21]. For studying the kinetics of insulin release and of cAMP in islets, a perifusion system similar to that first employed by Burr et al. [22] and modified by Lacy, Walker, and Fink [23] was used. Batches of 100 to 200 islets were used in each experiment. A $45 \mathrm{~min}$ preperifusion period was followed by stimulation with test substances for various time periods as indicated in the Results section. The 'dead space' of the perifusion system was $2.5 \mathrm{ml}$. In presenting the results an appropriate correction for the time delay in delivering the stimulus to the islet chamber, i.e. $2.5 \mathrm{~min}$ was introduced. Islets, still attached to the millipore filter, were then quickly removed from the chamber, submerged for $30 \mathrm{sec}$ in Freon-12 cooled to its freezing point $\left(-150^{\circ}\right)$ and then placed in glass jars for storage at $-80^{\circ} \mathrm{C}$. Cyclic AMP was extracted in $15 \%$ trichloroacetic acid $(0.5 \mathrm{ml} / \mathrm{batch}$ of 100 to 200 islets $)$. 
The acid extract was washed four times with 6 volumes of ethyl ether, and the acid-free solution was then dried with a stream of nitrogen. The solid residue was dissolved in $0.125 \mathrm{ml} 50 \mathrm{mM}$ sodium acetate buffer. With the extraction method used recovery of exogenous cyclic AMP was greater than $90 \%$.

The tissue extracts were assayed (in triplicate) for cyclic AMP using the radioimmunoassay of Steiner et al. $[24,25]$. Because of the small amount of tissue available it was necessary to modify the assay technique originally described. Only one tenth of the assay volumes recommended by Steiner et al. [25] were used. Therefore, each assay tube contained $30 \mu \mathrm{l}$ of standard or sample diluted in acetate buffer, $10 \mu 1$ of diluted rabbit anti-cyclic AMP antibody, $10 \mu 1$ of a solution of ${ }^{125}$ I labeled succinyl-cyclic AMP tyrosine methyl ester $(1200-1500 \mathrm{cpm}$ per $10 \mu \mathrm{l})$ and $2 \mu \mathrm{l}$ of goat anti-rabbit IgG. After all additions were made the tubes were incubated at $4^{\circ}$ for $18-24$ hours. To each assay tube $0.8 \mathrm{ml}$ water was then added and the tubes were centrifuged at $1250 \times \mathrm{g}$ for $30 \mathrm{~min}$. The supernatant fluid was decanted and discarded and the precipitate was counted in a gamma spectrometer. As a result of this modification, it was possible to measure as little as $7 \times 10^{-14}$ moles of cyclic AMP (Fig. 1).

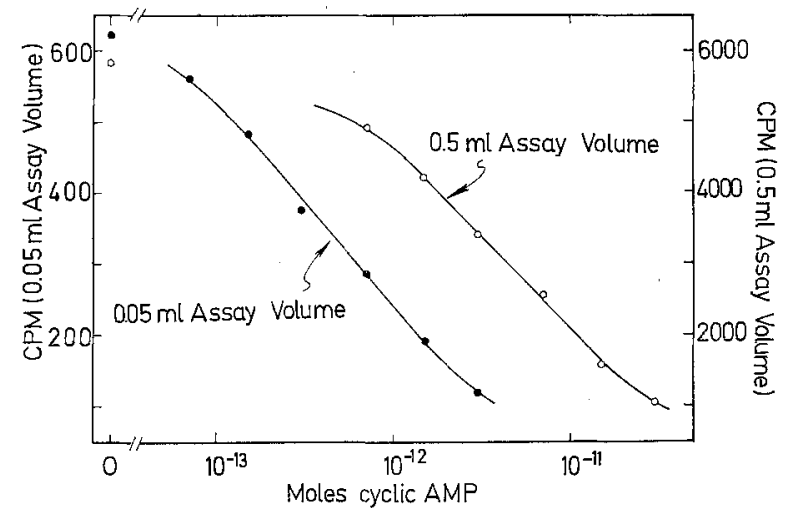

Fig. 1. Standard curve of the micro modification of the radioimmunoassay for $C A M P$. Each point represents the mean of three determinations

This is the amount of cyclic AMP present in 5-10 isolated islets under control conditions in the perifusion system. Assay variability with the modified method was less than 10\%; this is not different from the results with the originally described procedure (Fig. 1).

Treatment of tissue extracts of control and stimulated islets with phosphodiesterase resulted in a greater than $95 \%$ decrease in cyclic AMP concentration indicating that essentially all of the measured substance was, in fact, cyclic AMP.

The medium used to perifuse the islets was com- posed of $0.5 \%$ crystalline bovine serum albumin (Armour Pharmaceuticals) in a salt solution buffered with bicarbonate $(\mathrm{pH} 7.4)$ and continuously gassed with a mixture of $95 \% \mathrm{O}_{2}$ and $5 \% \mathrm{CO}_{2}$. The salt composition was $\mathrm{NaCl}, 115 \mathrm{mM} ; \mathrm{KCl}, 5 \mathrm{mM}$; $\mathrm{NaHCO}_{3}$, $24 \mathrm{mM} ; \mathrm{CaCl}_{2}, 2.1 \mathrm{mM} ; \mathrm{MgCl}_{2}, 1 \mathrm{mM}$. The flow rate was maintained close ( $\pm 10 \%$ ) to $1 \mathrm{ml} / \mathrm{min}$. Immunoreactive insulin was measured according to the method of Hales and Randle [28] using porcine insulin as a standard.

\section{Results}

Glucose stimulated insulin release was biphasic, displaying a first peak at $2 \mathrm{~min}$ and a delayed second phase (Fig. 2). The cAMP levels in the islets also changed in a biphasic fashion: at 2 min cAMP was increased 3.1 fold; at $5 \mathrm{~min}$, less dramatically, 1.4

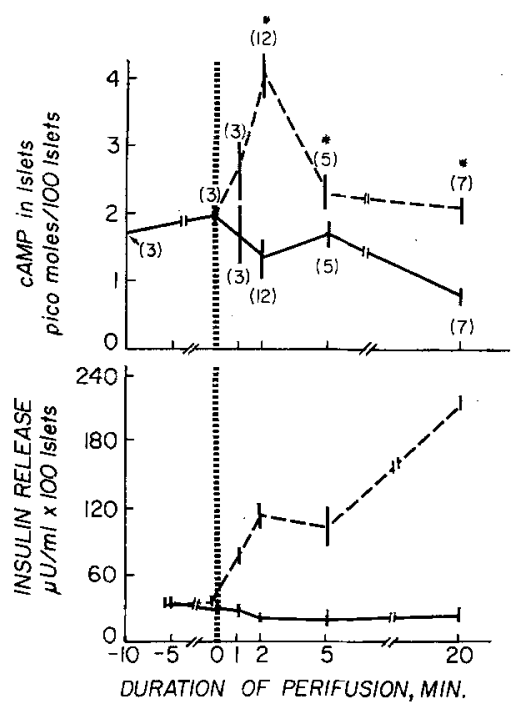

Fig. 2. Kinetics of insulin release and cAMP level changes in isolated perifused rat islets. In each experiment 200 islets were used. After establishing constant baselines of insulin release during a $45 \mathrm{~min}$ period using a medium containing basal glucose $(2.75 \mathrm{mM})$ the stimulatory medium containing high glucose $(27.5 \mathrm{mM})$ was fed into the system at $t_{0}$. The controls were maintained on the basal glucose level after a sham switch at $t_{0}$. The values recorded represent the means \pm SEM of an indicated number of experiments. The cAMP points marked with a star differ statistically from the controls, $(p \leq 0.05)$. All the differences of the insulin values after the switch to high glucose are statistically significant, $(p<0.01)$

fold and at $20 \mathrm{~min}, 2.8$ fold, whereas at $1 \mathrm{~min}$ the levels were not significantly different from the controls. In the controls the cAMP levels declined by $50 \%$ in the course of the time period analyzed ( $20 \mathrm{~min}$ ).

When $\mathrm{Ca}^{++}$was deleted from the perifusion medium, the increases induced by high glucose in 
Table 1. The influence of $\mathrm{Ca}^{++}$, mannoheptulose, and insulin on the glucose induced elevation of $c$ AMP levels in islets of Langerhans and on insulin release

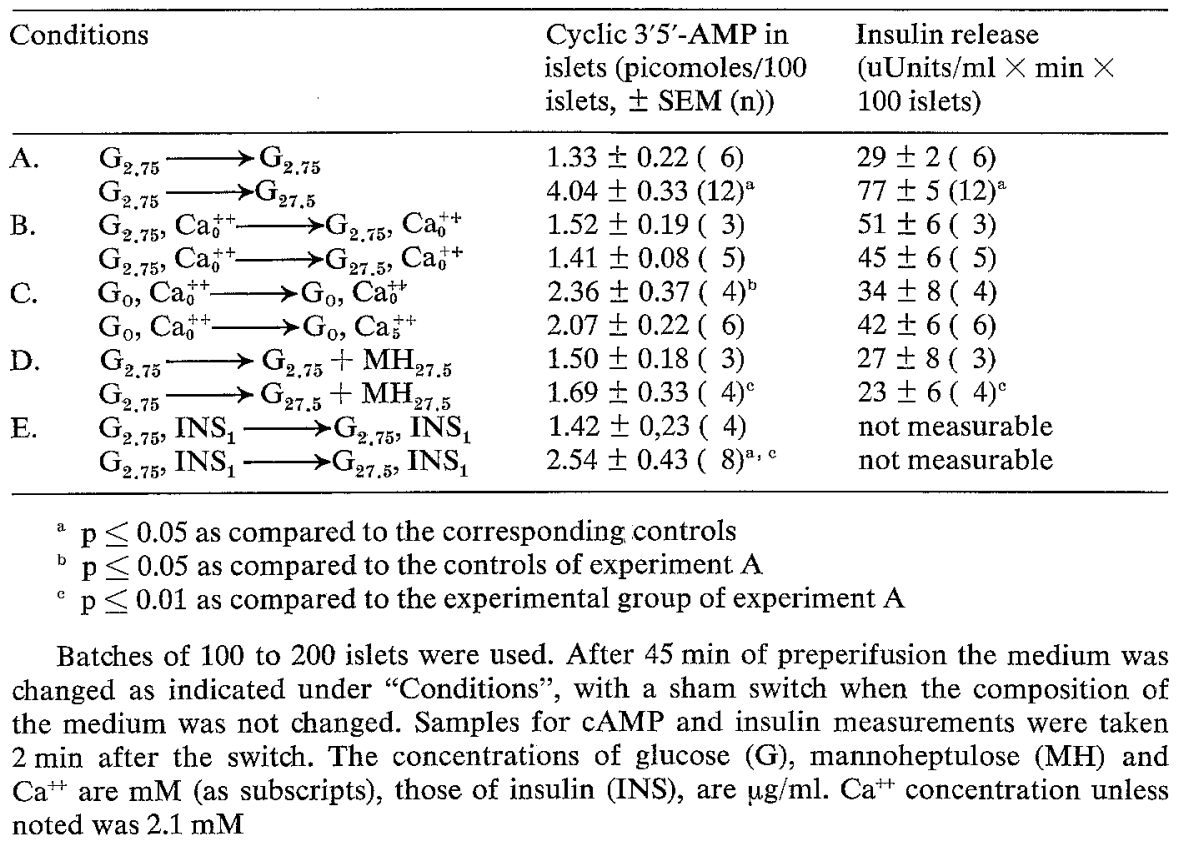

cAMP and insulin release were both blocked (Table 1, Experiment B). Basal release of insulin was however slightly increased under these conditions (compare $B$ with controls of $A$ ). In the absence of both $\mathrm{Ca}^{++}$and glucose, islet cAMP levels were $75 \%$ higher than in the presence of basal glucose and normal $\mathrm{Ca}^{++}$(compare controls of $\mathrm{A}$ and $\mathrm{C}$ ); readdition of $5 \mathrm{mM} \mathrm{Ca}^{++}$alone was unable to change cAMP significantly or to elicit hormone release, at least not within the time interval studied here $(2 \mathrm{~min})$, indicating that insulin release as well as cAMP elevation requires the simultaneous presence of $\mathrm{Ca}^{++}$and glucose (Experiment C). Equimolar mannoheptulose blocked completely the increase in cAMP and insulin release due to high glucose (Experiment $D$ ).

Porcine insulin at $1 \mu \mathrm{g} / \mathrm{ml}$ significantly inhibited the rise of cAMP due to high glucose (Experiment E). The use of such levels of extracellular insulin seemed justified because it was calculated that during maximal stimulation, the insulin level in the center of a pancreatic islet may amount to more than one $\mu \mathrm{g} / \mathrm{ml}$ of water (Table 2).

\section{Discussion}

The present experiments demonstrated that glucose stimulation of islets produced marked elevation of cAMP levels, a result also reported by Charles et al. [8], by Selawry et al. [10] by Grill and Cerasi [9, 12] as well as by Capito and Hedeskov [14] but not
Table 2. Theoretical diffusion profile of insulin in isolated islets

\begin{tabular}{|c|c|c|}
\hline \multirow[b]{2}{*}{$\begin{array}{l}\text { Distance from } \\
\text { center }(\mathrm{u})\end{array}$} & \multicolumn{2}{|c|}{ Concentration of free insulin $(\mu \mathrm{g} / \mathrm{ml})$} \\
\hline & $\begin{array}{l}\text { Nonstimulated } \\
\text { islet }\end{array}$ & $\begin{array}{l}\text { Stimulated } \\
\text { islet }\end{array}$ \\
\hline 0 & 0.342 & 1.68 \\
\hline 50 & 0.249 & 1.25 \\
\hline 75 & 0.147 & 0.745 \\
\hline 90 & 0.066 & 0.328 \\
\hline 95 & 0.036 & 0.177 \\
\hline
\end{tabular}

The insulin diffusion profiles of an average spherical islet with a diameter of $200 \mu$ were calculated according to $\mathbf{M}$. $\mathbf{H}$. Jacobs [26] using the following formula:

$$
\mathrm{u}=\mathrm{c}+\frac{\alpha}{6 \mathrm{D}}\left(\mathrm{R}^{2}-\mathrm{r}^{2}\right)
$$

where $\mathrm{u}=$ concentration of insulin at distance $\mathrm{r}$ from center $[\mu \mathrm{g} / \mathrm{ml}] ; \mathrm{c}=$ concentration of insulin at the surface $[\mu \mathrm{g} / \mathrm{ml}]$; $\alpha=$ rate of insulin secretion in steady state $[\mu \mathrm{g} / \mathrm{sec} \times \mathrm{ml}$ tissue $] . \mathrm{D}=$ diffusion constant of insulin $\left[\mathrm{cm}^{2} / \mathrm{sec}\right] ; \mathrm{R}=$ radius of sphere $[\mathrm{cm}] ; \mathrm{r}=$ distance from center of sphere $[\mathrm{cm}]$. In the example given $c$ is assumed to be $0.01 \mu \mathrm{g} / \mathrm{ml}$ and 0.002 $\mu \mathrm{g} / \mathrm{ml}$ and $\alpha$ is calculated to be 0.16 and $0.032 \mu \mathrm{g} / \mathrm{ml} \times \mathrm{sec}$ for the stimulated and the non stimulated islet, respectively.

$D$ for the monomeric insulin is $1.6 \times 10^{-6} \mathrm{~cm}^{2} / \mathrm{sec}$ [27]

confirmed by Cooper, Ashcroft and Randle [16] and Hellman et al. [17]. Reasons for these discrepancies are not readily apparent, but subtle differences in the procedures for isolating pancreatic islets with crude collagenase used by the several laboratories, species differences, or the nutritional state of the animal [14] seem to be the most likely causes. In the present study, 
the rise of the nucleotide level exhibited an early peak (300\% as compared to the appropriate control with low glucose). The relative elevation after $20 \mathrm{~min}$ with high glucose was equally pronounced $(2.1 \pm 0.15$ vs $0.8 \pm 0.1$ picomoles $/ 100$ islets) but the absolute level at that time was only one-half of the transient peak level of the nucleotide. Charles et al. also reported that cAMP levels were elevated 2 min after exposure to high glucose $(17 \mathrm{mM})$ but found that cAMP was as high or even higher after $20 \mathrm{~min}$ perifusion with high glucose [8]. Again, we have no sure explanation for the difference in the time course of CAMP response.

The rise of cyclic AMP might well be due to glucose activating adenylate cyclase. Although studies on islet homogenates have not revealed any direct effect of glucose on activation of adenylate cyclase it remains a distinct possibility that cellular integrity is a necessary prerequisite for this response. It seems less likely that inhibition of the $\mathrm{Ca}^{++}$and glucose insensitive phosphodiesterase is involved $[29,30]$. or incapable of inducing secretion $[1,2]$, it seems very probably that initiation of the release process by high glucose is accompanied by the simultaneous increase both of cAMP and of the islet $\mathrm{Ca}^{++}$content.

Mannoheptulose, as previously reported by Capito and Hedeskov [14] for mouse islets, blocked the accumulation of cAMP due to high glucose.

The preceding considerations lead to the conclusion that the elevation of cyclic AMP levels may be a requirement for glucose-induced insulin release. One might also speculate that the increase of cyclic AMP levels caused by high glucose levels might augment the responsiveness of B-cells to other stimuli that are present in the physiological setting, i.e., amino acids, ketone bodies, fatty acids. Finally, there is little doubt that the cyclic AMP system can serve to transmit the modulatory function of many hormones and neurotransmitters that are known to influence insulin release. A schematic representation of this concept is proposed in Fig. 3. The inhibition of the cAMP rise by high

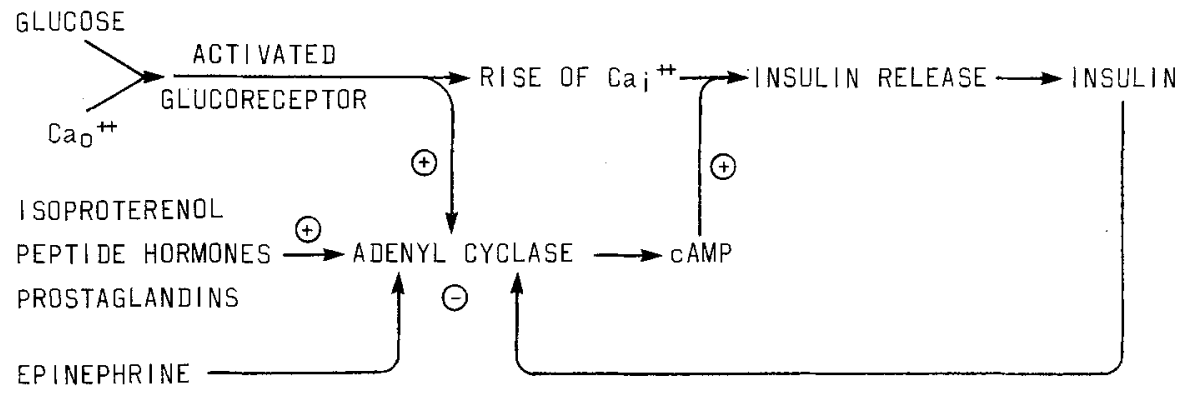

Fig. 3. The role of $c A M P$ in glucose induced insulin release. Based on the present data and related information in the literature a scheme is presented describing the possible roles of glucose, $\mathrm{Ca}^{++}$and $\mathrm{CAMP}$ in insulin release. Under physiological conditions glucose might activate a putative glucoreceptor [32] located in the cell membrane causing increased $\mathrm{Ca}^{++}$entry into the cell $[18,19]$. Concomitantly adenylate cyclase might be stimulated in a $\mathrm{Ca}^{+*}$-dependent manner. (It seems less likely that inhibition of the $\mathrm{Ca}^{++}$- and glucose insensitive phosphodiesterase is involved $[29,30]$. It remains, however undecided whether cAMP plays an obligatory role in glucose induced insulin discharge, or whether its role, although physiological, can be by-passed. Catecholamines, peptide hormones, prostaglandins and insulin are able to modulate the rate of release by altering the activity of adenylate cyclase most likely in a $\mathrm{Ca}^{+-}$- and glucose-independent manner $[1-7,18,19]$

It is assumed that the changes of cyclic AMP levels observed here occur in B-cells. However, one must not forget that islet tissue is heterogeneous (i.e. only $60-75 \%$ of the cells are B-cells), containing among others the functionally different but nevertheless glucose sensitive $\alpha$-cells (i.e. $10-25 \%$ ).

The calcium dependency of glucose-induced elevation of cAMP is remarkable since in many other systems with intact cells and in cell-free systems [19], $\mathrm{Ca}^{++}$is not required for a specific stimulus to produce an accumulation of cAMP. Since the stimulation of insulin release by glucose demands that extracellular $\mathrm{Ca}^{++}$be present [18] and since elevation of cAMP levels alone either by adding the nucleotide or by phosphodiesterase inhibitors is rather ineffective exogenous insulin may be compatible with the view that insulin functions as a feedback inhibitor of its release [20,31, see also 30]. Although the existence of this feedback has been recently questioned, [33] it may only become apparent when higher amounts of exogenous insulin are added. Fig. 3 also offers a hypothesis for the mechanism of this inhibition.

Acknowledgements. This work was supported by research grants AM 10591 and NS 09667 from the U.S.P.H.S. Dr. Zawalich is a recipient of a postdoctoral fellowship (NS 05221) and Drs. Ferrendelli and Matschinsky are recipients of Research Career Development Awards (NS 50292 and GM 42374, respectively). We also thank the Upjohn Company and Eli Lilly for grants-in-aid to conduct these studies. The expert technical assistance of Kathryn Troyer is gratefully acknowledged. 
The essential portions of the present study have appeared in abstract form (Diabetes 22, Suppl. 1, 331 (1973), Diabetes 23, 337 (1974)) and were presented by F.M.M. at the Membrane Conference at Squaw Valley, March 1973, and at the Meeting of the International Diabetes Federation in Brussels, July, 1973.

\section{References}

1. Brisson, G. R., Malaisse-Lagae, F., Malaisse, W. J.: The stimulus-secretion coupling of glucose-induced insulin release. VII. A proposed site of action for adenosine $3^{\prime}, 5^{\prime}-$ cyclic monophosphate. J. clin. Invest. 51, 232-241 (1972)

2. Sussman, K. E., Vaughan, G. P.: Insulin release after ACTH, glucagon and adenosine- $3^{\prime}-5^{\prime}$-phosphate (cyclic AMP) in the perfused isolated rat pancreas. Diabetes $\mathbf{1 6}$, 449-454 (1967)

3. Malaisse, W., Malaisse-Lagae, F., Wright, P. H., Ashmore, J.: Effects of adrenergic and cholinergic agents upon insulin secretion in vitro. Endocrinology 80, 975-978 (1967)

4. Malaisse, W., Malaisse-Lagae, F.: Insulin secretion by isolated islets of Langerhans. Effects of pancreatic and intestinal hormones. Acta diabet. lat. 5, 64 - 72 (1968)

5. Vance, J. E., Buchanan, K. D., Williams, R. H.: Glucagon and insulin release. Influence of drugs affecting the autonomic nervous system. Diabetes 20, 78-82 (1971)

6. Coore, A. G., Randle, P. F.: Regulation of insulin secretion studied with pieces of rabbit pancreas incubated in vitro. Biochem. J, 93, 66-78 (1964)

7. Turtle, J. R., Kipnis, D. M.: An adrenergic receptor mechanism for the control of cyclic $35^{\prime}$-adenosine monophosphate synthesis in tissues. Biochem. biophys. Res. Commun. 28, 797-802 (1967)

8. Charles, M. A., Fanska, R., Schmid, F. G., Forsham, P. H., Grodsky, G. M.: Adenosine 3',5'-monophosphate in pancreatic islets: glucose-induced insulin release. Science 179, 569-571 (1973)

9. Grill, V., Cerasi, E.: Activation by glucose of adenyl cyclase in pancreatic islets of the rat. Fed. Europ. Biochem. Soc. Lett. 33, 311-314 (1973)

10. Selawry, H., Marcks, C., Fink, G., Lavine, R., Cresto, J., Recant, L.: A mechanism for glucose-induced insulin release. Diabetes 22, 295 (Abstr.) (1973)

11. Zawalich, W. S., Ferrendelli, J., Matschinsky, F. M.: Glucose-induced elevation of cyclic $3^{\prime}, 5^{\prime}$-AMP (cAMP) levels in pancreatic islets. Diabetes 22, (Abstr.) 331 (1973)

12. Grill, V., Cerasi, E.: Stimulation by D-glucose of cyclic adenosine $3^{\prime}-5$ '-monophosphate accumulation and insulin release in isolated pancreatic islets of the rat. J. biol. Chem. 249, 4196-4201 (1974)

13. Zawalich, W. S., Karl, R. C., Ferrendelli, J., Matschinsky, F. M.: Effects of glucose, $\mathrm{Ca}^{++}$, and an ionophore on cyclic-3'5'-AMP (cAMP) and insulin release in isolated pancreatic islets. Diabetes 23, 337 (Abstr.) (1974)

14. Capito, K., Hedeskov, C. J.: The effect of starvation on phosphodiesterase activity and the content of adenosine $3^{\prime}-5^{\prime}$-cyclic monophosphate in isolated mouse pancreatic islets. Biochem. J. 142, 653-658 (1974)

15. Montague, W., Cook, J. R.: The role of adenosine 3'5'cyclic monophosphate in the regulation of insulin release by isolated rat islets of Langerhans. Biochem. J. 122, 115-$120(1971)$
16. Cooper, R. H., Ashcroft, S. J. H., Randle, P. J.: Concentration of adenosine $3^{\prime}, 5^{\prime}$-cyclic monophosphate in mouse pancreatic islets measured by a protein binding radioassay. Biochem. J. 134, 599-605 (1973)

17. Hellman, B., Idahl, L. A., Lernmark, A., Täljedal, I. B.: The pancreatic $\beta$-cell recognition of insulin secretagogues: Does cyclic AMP mediate the effect of glucose. Proc. nat. Acad. Sci. (Wash.) 71, 3405-3409 (1974)

18. Curry, D. L., Bennett, L. L., Grodsky, G. M.: Requirement for calcium ion in insulin secretion by the perfused rat pancreas. Amer. J. Physiol. 214, 172-174 (1968)

19. Rasmussen, H.: Cell communication, calcium ion, and cyclic adenosine monophosphate. Science 170, 404-412 (1970)

20. Iversen, J., Miles, D. W.: Evidence for a feedback inhibition of insulin secretion in the isolated, perfused canine pancreas. Diabetes 20,1-9 (1971)

21. Lacy, P. E., Kostianovsky, M.: Method for the isolation of intact islets of Langerhans from the rat pancreas. Diabetes 16, 35-39 (1967)

22. Burr, I. M., Stauffacher, W., Balant, L., Renold, A. E., Grodsky, G. M.: Regulation of insulin release in perifused pancreatic tissue. Acta diabet. lat. 6, 580-589 (1969)

23. Lacy, P. E., Walker, M. M., Fink, C. J.: Perifusion of isolated rat islets in vitro. Participation of the microtubular system in the biphasic release of insulin. Diabetes 21, 987-998 (1972)

24. Steiner, A. L., Parker, C. W., Kipnis, D. M.: Radioimmunoassay for cyclic nucleotides. J. biol. Chem. 247, $1106-1113(1972)$

25. Steiner, A. L., Kipnis, D. M., Utiger, R., Parker, C.: Radioimmunoassay for the measurement of adenosine 3'5'-cyclic monophosphate. Proc. nat. Acad. Sci. (Wash.) 64, 367-373 (1969)

26. Jacobs, M. H.: Diffusion Processes, p. 142. Berlin-Heidelberg-New York: Springer-Verlag 1967

27. Netter, H.: Theoretische Biochemie, p. 312. Berlin-Göttingen-Heidelberg: Springer-Verlag 1959

28. Hales, C. N., Randle, P. J.: Immunoassay of insulin with insulin-antibody precipitate. Biochem. J. 88, 137-146 (1963)

29. Cheung, W. Y.: Role of Cyclic AMP in Cell Function, p. 51. New York: Raven Press 1970

30. Kuo, W. N., Hodgins, D. S., Kuo, J. F.: Adenylate cyclase in islets of Langerhans. J. biol. Chem. 248, 2705-2711 (1973)

31. Sodoyez, J.-C., Sodoyez-Goffaux, F., Foa, P. P.: Structure and metabolism of the pancreatic islets, p. 445. Oxford: Pergamon Press 1970

32. Matschinsky, F. M., Landgraf, R., Ellerman, J., KotlerBrajtburg, J.: Glucoreceptor mechanisms in islets of Langerhans. Diabetes 21 (Suppl. 2), 555-569 (1972)

33. Grodsky, G. M., Fanska, R., Schmid, F. G.: Evaluation of the role of exogenous insulin on phasic insulin secretion. Diabetes 22, 256-263 (1973)

Dr. W. S. Zawalich

Department of Pharmacology

Washington University

Medical School

660 S. Euclid Avenue

St. Louis

Missouri 63110

USA 